\title{
Induction of tolerance in clinical kidney transplantation
}

\author{
Tatsuo Kawai and A. Benedict Cosimi \\ Massachusetts General Hospital, Transplant Center, Harvard Medical School, Boston, MA, USA
}

\begin{abstract}
Induction of donor-specific tolerance has been an ultimate goal in organ transplantation. Although numerous regimens for the induction of allograft tolerance have been developed in rodents, their application to primates has been limited. The approaches that have been successfully applied in primates can be divided into (i) use of total lymphoid irradiation, (ii) costimulatory blockade, (iii) profound depletion of recipient $\mathrm{T}$ cells, (iv) infusion of regulatory cells and (v) donor bone marrow (DBM) infusion/transplantation. Among these approaches, successful allograft tolerance has been achieved in clinical kidney transplantation using DBM transplantation.
\end{abstract}

\begin{abstract}
Since the advent of calcineurin inhibitors and other potent immunosuppressive medications, a significant improvement has been achieved in short-term results following organ transplantation. However, long-term results have been less satisfactory (1), mainly attributable to chronic rejection and the toxicities of immunosuppressive drugs (2). Therefore, induction of specific immunologic tolerance remains an important goal of organ transplantation. Since the pioneering work of Billingham, Brent and Medawar more than 50 yr ago (3), many tolerance induction strategies have been developed in rodent models. However, a limited number of strategies have been successfully translated to non-human primates (NHP) and even fewer to humans.
\end{abstract}

\section{Strategies to induce tolerance in NHP and clinical trials}

Various strategies to induce allograft tolerance have been attempted in non-human primates (NHP) and humans. These strategies include (i) use of total lymphoid irradiation (TLI) (4-7); (ii) costimulatory blockade (8-14); (iii) profound depletion of recipient T cells (15-23); (iv) infusion of regulatory cells (24); and (v) donor bone marrow (DBM) infusion/ transplantation (25). However, among these approaches, induction of mixed chimerism through DBM transplantation is the only approach that has been successfully translated to a consecutive series of kidney transplant patients to date.

\section{Tolerance through the mixed chimerism approach}

In contrast to the myeloablative regimens utilized when bone marrow transplantation (BMT) is performed to treat malignancies, the conditioning regimens used for induction of mixed

(C) 2010 John Wiley \& Sons A/S.

Corresponding author: Tatsuo Kawai, MD, Massachusetts General Hospital, Whte 521, 55 Fruit St. Boston, MA 02114, USA. Tel.: 617726 0289; fax: 617726 9322; tatkawai@ verizon.net.

Conflict of interests: The authors do not have potential conflict of interests in this work. 
chimerism have generally been non-myeloablative, in which case recipients should be able to recover from pancytopenia even without engraftment of DBM cells. The chimerism induced after such non-myeloablative regimens is generally characterized as "mixed chimerism," a state in which both donor and recipient hematopoiesis coexist.

\section{The mixed chimerism approach in NHP}

Based on previous rodent studies of mixed chimerism $(26,27)$, we developed a clinically relevant, non-myeloablative preparative regimen that permitted the induction of mixed chimerism and renal allograft tolerance following donor bone marrow transplantation (DBMT) in MHC fully mismatched cynomolgus monkeys (28-30). Elements of the initial preparative regimen for monkeys included total body irradiation $(\mathrm{TBI})(150 \mathrm{cGy} \times 2)$, plus local thymic irradiation (700 cGy), horse anti-thymocyte globulin (ATG), splenectomy or anti-CD154 mAb, DBM and a one-month post-transplant course of cyclosporine. With this approach, 50-60\% of cynomolgus monkey recipients acquired renal allograft tolerance, with the longest survival currently exceeding $14 \mathrm{yr}(30,31)$. Unlike the previous rodent studies, mixed chimerism observed in NHP has been transient $(29,30,32)$ and continued survival of the kidney allograft despite the loss of chimerism suggests that peripheral mechanisms are also operative.

The major drawback of our current protocol has been inapplicability in diseased donor kidney transplantation, because the conditioning needs to be initiated a week before transplantation. Therefore, we have recently developed a "Delayed Tolerance" protocol, in which non-human primate recipients first undergo kidney transplantation with conventional immunosuppression, followed by the conditioning and DBMT several months after kidney transplantation. In our initial studies, the previously successful living donor regimen induced mixed chimerism when delayed DBMT was performed at four months after kidney transplantation, if effective depletion of CD8 memory T cells was included (33). Further studies are currently underway to improve the efficacy of the "Delayed Tolerance" protocol.

\section{The mixed chimerism approach in clinical kidney transplantation}

Mixed chimerism approach in HLA identical kidney transplantation-Using TLI and DBMT, successful induction of stable mixed chimerism and renal allograft tolerance has been reported in human leukocyte antigen (HLA) identical kidney transplantation (34). After kidney transplantation, a recipient was conditioned with TLI (80 cGy $\times 10$, days $1-14)$, antirabbit thymocyte globulin $(1.5 \mathrm{mg} / \mathrm{kg} \times 5$, days $0-4)$, and received HLA-matched peripheral blood stem cells on day 14 . The patient was treated with triple immunosuppressive therapy (mycophenolate mofetil, prednisone, and cyclosporine) after transplantation, but all immunosuppressive medications were slowly tapered off over six months. The patient has been doing well with normal kidney function with stable mixed chimerism for more than 28 months without immunosuppression. An advantage of their approach would be applicability to deceased donor transplantation, because all treatments in their regimen are initiated after organ transplantation.

At Massachusetts General Hospital (MGH), a total of seven patients with renal failure secondary to multiple myeloma have received HLA identical combined kidney and bone 
marrow transplantation (CKBMT) after conditioned with a non-myeloablative regimen. The preparative regimen consisted of cyclophosphamide $(60 \mathrm{mg} / \mathrm{kg} \times 2)$, local thymic irradiation $700 \mathrm{cGy}$, horse ATG and a 60-d course of post-transplant cyclosporine administration (35-37). All recipients developed mixed chimerism, but it became undetectable by day 100 after CKBMT in four of seven patients. Nevertheless, remission of the myeloma was observed in three of the four patients with transient chimerism, suggesting a graft versus leukemia (GVL) effect despite loss of chimerism. Immunosuppression was successfully withdrawn in all four recipients with transient chimerism with the longest kidney allograft survival exceeding $10 \mathrm{yr}$. Mixed chimerism converted to full chimerism in two patients, one spontaneously and the other after donor lymphocyte infusion. One of them achieved complete remission of his myeloma but has been on mycophenolate mofetil and steroids to prevent graft versus host disease (GVHD). The other patient with full chimerism lost her renal function as a consequence of myeloma recurrence. The last patient developed stable mixed chimerism with stable renal function for longer than three yr without immunosuppression. These observations demonstrate that CKBMT with a nonmyeloablative regimen from an HLA-matched donor can be an excellent option for renal failure secondary to myeloma, where no effective treatment option has been available.

Mixed chimerism in HLA-mismatched kidney transplantation-After the report on neonatal tolerance by Medawar et al., (3), an attempt to induce immunological tolerance in kidney transplantation was made by Murray et al. (38) in late 1950s. Because effective immunosuppressive medications were not yet available at that time, the patients were treated with sublethal doses (250-700 cGy) of total body irradiation. Most recipients (five of six) died from either the toxicity of the regimen or the infection. After this clinical trial, efforts in transplant immunology shifted to developing effective immunosuppressive medications (39), and BMT for tolerance induction was not investigated further until recently.

As described above, the Stanford group also attempted peripheral blood stem cell transplantation with a TLI-based regimen for induction of renal allograft tolerance in HLAmismatched kidney transplantation (40). In this clinical trial, three of four recipients developed transient multilineage chimerism but rejection developed when immunosuppression withdrawal was attempted (40). These investigators concluded that this protocol did not induce allograft tolerance in HLA-mismatched recipients (41).

At MGH, using a non-myeloablative regimen, five patients underwent CKBMT from onehaplotype-mismatched siblings or parents (42). All recipients developed transient mixed chimerism, lasting up to $21 \mathrm{~d}$. Although one of these patients developed acute humoral rejection, immunosuppression was successfully discontinued in 9-14 months in the other four of these five recipients. The first patient is now almost $7 \mathrm{yr}$ since transplant. All showed donor-specific unresponsiveness by in vitro assays but the mechanism responsible for stable graft function without exogenous immunosuppression in these recipients remains under investigation. These four recipients continue to be stable with normal kidney function off all immunosuppression for 4-7 yr. Two of these recipients developed anti-donor HLA class II antibody shortly after immunosuppression discontinuation, but have had no functional impairment, nor evidence of rejection on sequential protocol biopsies. An adverse event observed in these patients have been developed derangement of renal function between days 
10-20, which was attributed to cytokine release (engraftment syndrome) associated with engraftment and/or loss of donor hematopoietic cells. All showed donor-specific unresponsiveness by in vitro assays but the mechanism responsible for stable graft function without exogenous immunosuppression in these recipients remains under investigation.

Since January 2009, a new clinical trial for tolerance induction for HLA-mismatched kidney transplantation has been underway using the revised protocol.

\section{References}

1. Meier-Kriesche HU, Schold JD, Srinivas TR, Kaplan B. Lack of improvement in renal allograft survival despite a marked decrease in acute rejection rates over the most recent era. Am J Transplant. 2004; 4:378. [PubMed: 14961990]

2. Pascual M, Theruvath T, Kawai T, Tolkoff-Rubin N, Cosimi AB. Strategies to improve long-term outcomes after renal transplantation. N Engl J Med. 2002; 346:580. [PubMed: 11856798]

3. Billingham RE, Brent L, Medawar PB. Activity acquired tolerance of foreign cells. Nature. 1953; 172:603. [PubMed: 13099277]

4. Slavin S, Gottlieb M, Strober S, et al. Transplantation of bone marrow in outbred dogs without graft-versus-host disease using total lymphoid irradiation. Transplantation. 1979; 27:139. [PubMed: 37616]

5. Myburgh JA, Smit JA, Stark JH, Browde S. Total lymphoid irradiation in kidney and liver transplantation in the baboon: prolonged graft survival and alterations in $\mathrm{T}$ cell subsets with low cumulative dose regimens. J Immunol. 1984; 132:1019. [PubMed: 6228586]

6. Strober S, Dhillon M, Schubert M, et al. Acquired immune tolerance to cadaveric renal allografts. A study of three patients treated with total lymphoid irradiation. N Engl J Med. 1989; 321:28. [PubMed: 2525231]

7. Strober S, Benike C, Krishnaswamy S, Engleman EG, Grumet FC. Clinical transplantation tolerance twelve years after prospective withdrawal of immunosuppressive drugs: studies of chimerism and anti-donor reactivity. Transplantation. 2000; 69:1549. [PubMed: 10836360]

8. Kirk AD, Tadaki DK, Celniker A, et al. Induction therapy with monoclonal antibodies specific for CD80 and CD86 delays the onset of acute renal allograft rejection in non-human primates. Transplantation. 2001; 72:377. [PubMed: 11502964]

9. Kirk AD, Harlan DM, Armstrong NN, et al. CTLA4-Ig and anti-CD40 ligand prevent renal allograft rejection in primates. Proc Natl Acad Sci USA. 1997; 94:8789. [PubMed: 9238056]

10. Kirk AD, Burkly LC, Batty DS, et al. Treatment with humanized monoclonal antibody against CD154 prevents acute renal allograft rejection in nonhuman primates. Nat Med. 1999; 5:686. [PubMed: 10371508]

11. Kirk ADKS, Sollinger HW, Vincenti F, Stecher S, Nadeau K. Preliminary results of the use of humanized anti-CD154 in human renal allotransplantation. Am J Transplant. 2001; 1:S191.

12. Chen G, Luke PP, Yang H, et al. Anti-CD45RB monoclonal antibody prolongs renal allograft survival in cynomolgus monkeys. Am J Transplant. 2007; 7:27. [PubMed: 17227555]

13. Larsen CP, Pearson TC, Adams AB, et al. Rational development of LEA29Y (belatacept), a highaffinity variant of CTLA4-Ig with potent immunosuppressive properties. Am J Transplant. 2005; 5:443. [PubMed: 15707398]

14. Vincenti F, Larsen C, Durrbach A, et al. Costimulation blockade with belatacept in renal transplantation. N Engl J Med. 2005; 353:770. [PubMed: 16120857]

15. Neville DM Jr, Scharff J, Srinivasachar K. In vivo T-cell ablation by a holo-immunotoxin directed at human CD3. Proc Natl Acad Sci USA. 1992; 89:2585. [PubMed: 1372981]

16. Knechtle SJ, Vargo D, Fechner J, et al. FN18-CRM9 immunotoxin promotes tolerance in primate renal allografts. Transplantation. 1997; 63:1. [PubMed: 9000652]

17. Knechtle SJ, Kirk AD, Fechner JH Jr, et al. Inducing unresponsiveness by the use of anti-CD3 immunotoxin, CTLA4-Ig, and anti-CD40 ligand. Transplant Proc. 1999; 31(3B Suppl):27S. [PubMed: 10330966] 
18. Calne R, Friend P, Moffatt S, et al. Prope tolerance, perioperative campath $1 \mathrm{H}$, and low-dose cyclosporin monotherapy in renal allograft recipients. Lancet. 1998; 351:1701. [PubMed: 9734890]

19. Starzl TE, Murase N, Abu-Elmagd K, et al. Tolero-genic immunosuppression for organ transplantation. Lancet. 2003; 361:1502. [PubMed: 12737859]

20. Shapiro R, Basu A, Tan H, et al. Kidney transplantation under minimal immunosuppression after pretransplant lymphoid depletion with Thymoglobulin or Campath. J Am Coll Surg. 2005; 200:505. [PubMed: 15804464]

21. Contreras JL, Wang PX, Eckhoff DE, et al. Peritransplant tolerance induction with anti-CD3immuno-toxin: a matter of proinflammatory cytokine control. Transplantation. 1998; 65:1159. [PubMed: 9603161]

22. Thomas JM, Contreras JL, Jiang XL, et al. Peritransplant tolerance induction in macaques: early events reflecting the unique synergy between immunotoxin and deoxyspergualin. Transplantation. 1999; 68:1660. [PubMed: 10609942]

23. Kirk AD, Hale DA, Mannon RB, et al. Results from a human renal allograft tolerance trial evaluating the humanized CD52-specific monoclonal antibody ale-mtuzumab (CAMPATH-1H). Transplantation. 2003; 76:120. [PubMed: 12865797]

24. Bashuda H, Kimikawa M, Seino K, et al. Renal allograft rejection is prevented by adoptive transfer of anergic T cells in nonhuman primates. J Clin Invest. 2005; 115:1896. [PubMed: 15951837]

25. Starzl TE, Demetris AJ. Transplantation tolerance, microchimerism, and the two-way paradigm. Theor Med Bioeth. 1998; 19:441. [PubMed: 10023193]

26. Tomita Y, Khan A, Sykes M. Role of intrathymic clonal deletion and peripheral anergy in transplantation tolerance induced by bone marrow transplantation in mice conditioned with a nonmyeloablative regimen. J Immunol. 1994; 153:1087. [PubMed: 8027542]

27. Sharabi Y, Sachs DH. Mixed chimerism and permanent specific transplantation tolerance induced by a nonlethal preparative regimen. J Exp Med. 1989; 169:493. [PubMed: 2562984]

28. Kawai T, Hoshino T, Fujioka S, et al. Mixed chimerism and immune tolerance induction by lowstress pretreatment before kidney transplantation in monkeys. Nihon Rinsho Meneki Gakkai Kaishi. 1995; 18:670. [PubMed: 8963780]

29. Kimikawa M, Sachs DH, Colvin RB, Bartholomew A, Kawai T, Cosimi AB. Modifications of the conditioning regimen for achieving mixed chimerism and donor-specific tolerance in cynomolgus monkeys. Transplantation. 1997; 64:709. [PubMed: 9311707]

30. Kawai T, Poncelet A, Sachs DH, et al. Long-term outcome and alloantibody production in a nonmyeloablative regimen for induction of renal allograft tolerance. Transplantation. 1999; 68:1767. [PubMed: 10609955]

31. Kawai T, Sogawa H, Boskovic S, et al. CD154 blockade for induction of mixed chimerism and prolonged renal allograft survival in nonhuman primates. Am J Transplant. 2004; 4:1391. [PubMed: 15307826]

32. Kawai T, Cosimi AB, Colvin RB, et al. Mixed allogeneic chimerism and renal allograft tolerance in cynomolgus monkeys. Transplantation. 1995; 59:256. [PubMed: 7839449]

33. Koyama I, Nadazdin O, Boskovic S, et al. Depletion of CD8 memory T cells for induction of tolerance of a previously transplanted kidney allograft. Am J Transplant. 2007; 7:1055. [PubMed: 17286617]

34. Scandling JD, Busque S, Dejbakhsh-Jones S, et al. Tolerance and chimerism after renal and hematopoietic-cell transplantation. N Engl J Med. 2008; 358:362. [PubMed: 18216356]

35. Spitzer TR, Delmonico F, Tolkoff-Rubin N, et al. Combined histocompatibility leukocyte antigenmatched donor bone marrow and renal transplantation for multiple myeloma with end stage renal disease: the induction of allograft tolerance through mixed lymphohematopoietic chimerism. Transplantation. 1999; 68:480. [PubMed: 10480403]

36. Buhler LH, Spitzer TR, Sykes M, et al. Induction of kidney allograft tolerance after transient lymphohe-matopoietic chimerism in patients with multiple myeloma and end-stage renal disease. Transplantation. 2002; 74:1405. [PubMed: 12451240] 
37. Fudaba Y, Spitzer TR, Shaffer J, et al. Myeloma responses and tolerance following combined kidney and nonmyeloablative marrow transplantation: in vivo and in vitro analyses. Am $\mathrm{J}$ Transplant. 2006; 6:2121. [PubMed: 16796719]

38. Murray JE, Merrill JP, Dammin GJ, et al. Study on transplantation immunity after total body irradiation: clinical and experimental investigation. Surgery. 1960; 48:272. [PubMed: 14425430]

39. Merrill JPMJ, Harrison JH, Friedman EA, Dealy JB, Dammin GJ. Successfu homotransplantation of the kidney between nonidentical twins. N Engl J Med. 1960; 262:1251.

40. Millan MT, Shizuru JA, Hoffmann P, et al. Mixed chimerism and immunosuppressive drug withdrawal after HLA-mismatched kidney and hematopoietic progenitor transplantation. Transplantation. 2002; 73:1386. [PubMed: 12023614]

41. Millan MTSJ, Shizuru J, Lowsky R, Strober S. Studies of tolerance and chimerism after combined blood stem cell and kidney transplantation in humans. Am J Transplant. 2005; 5(Suppl 11):544. [PubMed: 15707409]

42. Kawai T, Cosimi AB, Spitzer TR, et al. HLA-mismatched renal transplantation without maintenance immunosuppression. N Engl J Med. 2008; 358:353. [PubMed: 18216355] 